\title{
Analisis Bibliometrik Pada Scholarly Journals Proquest Dengan Kata Kunci "Tourism In Indonesia" Menggunakan Perangkat Lunak Vosviewer
}

\author{
Hendi Prasetyo \\ Program Studi S-1 Pariwisata, Sekolah Tinggi Pariwisata Ambarrukmo (STIPRAM) Yogyakarta \\ Jalan Ahmad Yani No. 52B Ringroad Timur, Modalan, Banguntapan, Bantul, \\ Daerah IstimewaYogyakarta \\ E-mail : hendi@stipram.ac.id
}

\begin{abstract}
Abstrak
Penelitian ini bertujuan untuk mengetahui peta perkembangan penelitian yang berkaitan dengan "Tourism in Indonesia". Penelitian ini dilakukan pada bulan September-Oktober 2020 dengan melakukan penelusuran melalui ProQuest. Peneliti menggunakan kata kunci "Tourism in Indonesia" untuk menghasilkan penelusuran agar lebih spesifik dengan kategori scholarly journals dan memiliki subject tourism. Pada penelitian ini, peneliti menggunakan metode deskriptif kuantitatif dengan analisis bibliometrika. Berdasarkan hasil penelusuran, peneliti memperoleh 56 hasil penelusuran karya ilmiah yang kemudian di export dalam format RIS dan diolah menggunakan VOSviewer. Berdasarkan hasil analisis, penelitian ini menunjukkan bahwa kata kunci (Co-Occurrence) terbagi dalam 3 cluster yang memiliki total 17 topik. Berdasarkan kolaborasi penulis (Co-Authorship) memiliki 1 cluster yang didalamnya memuat 23 penulis. Dari total 56 hasil penelusuran karya ilmiah, untuk penulis yang paling produktif adalah Jaelani, Aan dengan 3 dokumen hasil karya artikel jurnal. Sedangkan, penelitian dengan kata kunci "Tourism in Indonesia" mengalami perkembangan secara fluktuatif dan untuk terbitan terbanyak terjadi pada tahun 2019 dengan jumlah 11 terbitan.
\end{abstract}

Kata Kunci : Tourism in Indonesia, VOSviewer, ProQuest

\section{Bibliometric Analysis On Scholarly Journals Proquest With Keywords "Tourism In Indonesia" Using Vosviewer Software}

\begin{abstract}
This research aims to determine the map of research developments related to "Tourism in Indonesia". This research was conducted in September-October 2020 by searching through ProQuest. Researchers use the keyword "Tourism in Indonesia" to produce searches to be more specific in the category of scholarly journals and subject to tourism. In this research, researchers used quantitative descriptive methods with bibliometric analysis. Based on the search results, the researcher obtained 56 tracing results of scientific papers which were then exported in RIS format and processed using VOSviewer. Based on the results of the analysis, this research shows that the keywords (CoOccurrence) are divided into 3 clusters which have a total of 17 topics. Based on co-authorship, it has 1 cluster which contains 23 authors. From a total of 56 scientific research results, the most productive authors were Jaelani, Aan with 3 documents from journal articles. Meanwhile, research with the keyword "Tourism in Indonesia" has experienced fluctuating developments and the largest number of publications occurred in 2019 with 11 publications.
\end{abstract}

Keywords: Tourism in Indonesia, VOSviewer, ProQuest

\section{PENDAHULUAN}

Pariwisata merupakan salah satu objek yang menarik untuk dikaji. Hal ini dapat dilakukan karena pariwisata memiliki beragam potensi objek yang baik untuk dijadikan sebuah karya tulis. Damanik (2017) menyebut bahwa pariwisata memiliki sifat yang sangat dinamis dan cepat berubah. Setiap unsur dalam sistem pariwisata berkaitan dengan unsur eksternal yang sekaligus (dan sering) menjadi pemicu perubahan tersebut.

Kemajuan teknologi dengan jelas mengubah produk wisata. Produk pariwisata (tourism product) merupakan suatu bentukan yang nyata (tangible product) dan tidak nyata (intangible product) (Suryadana \& Octavia, 2015). Produk pariwisata ini merupakan suatu paket yang didalamnya dapat memenuhi 
kebutuhan wisatawan dari mulai ia meninggalkan hingga kembali ke tempat asalnya. Selain berkaitan dengan produk pariwisata, hal yang menarik untuk dikaji dalam bidang pariwisata ialah berkaitan dengan pola perjalanan wisata yang dilakukan oleh wisatawan. Hermantoro (2011) menyebut Plog membagi pola perjalanan wisataan menjadi 2 jenis, yaitu jenis allo-centric serta jenis psycho-centric. Jenis allo-centric merupakan tipe wisatawan yang siap mengalami bermacam efek serta hal-hal baru dalam ekspedisi wisatanya. Sebaliknya jenis psyho-centric ialah kelompok sosial yang tidak menggemari lingkungan ataupun juga budaya baru yang belum dikenalnya.

Berbagai hal yang merupakan bagian dari wisata diatas menggambarkan bahwa sesungguhnya, kajian-kajian berkaitan dengan penelitian dalam pariwisata dapat dilakukan lebih banyak lagi dan dapat dikaji secara luas misalnya pada industri pariwisata nya, apalagi penelitian di bidang pariwisata dapat dijadikan sebagai rujukan, evaluasi, dan pengembangan pariwisata di masa depan. Oleh sebab itu, peneliti akan melakukan analisis bibliometrik untuk mengetahui secara kuantitatif melalui karya ilmiah yang pernah dipublikasikan berkaitan dengan pariwisata khususnya hal-hal yang memuat tentang "Tourism in Indonesia".

Analisis bibliometrik adalah metode yang digunakan untuk menganalisis data bibliografi yang diperoleh dari berbagai literatur seperti artikel, jurnal, dan literatur lainnya. Dalam penelitian ini, peneliti menggunakan data set scholarly journals yang diperoleh dari Proquest dengan kata kunci "Tourism in Indonesia". Namun, berdasarkan hasil penelusuran, peneliti hanya memperoleh 56 hasil penelusuran spesifik karya ilmiah yang pernah dipublikasikan. Oleh sebab itu, penelitian ini harus dilakukan untuk mengukur dan melihat produktivitas serta perkembangan publikasi (peta riset) hasil penelitian dalam beberapa aspek seperti co-occurence (kata kunci) dan co-authorship (kolaborasi penulis) dari tahun ke tahun secara kuantitatif pada scholarly journals yang memuat kata kunci "Tourism in Indonesia" yang kemudian diolah menggunakan perangkat lunak VOSviewer. Hasil penelitian ini diharapkan dapat bermanfaat bagi para penulis dan peneliti pada bidang pariwisata untuk mengembangkan karya ilmiah berkaitan dengan pariwisata yang ada di Indonesia dengan melihat hasil cooccurence (kata kunci) yang memiliki peluang untuk dikaji lebih lanjut dan dapat dilihat juga terkait co-authorship (kolaborasi penulis) / produktivitas penulis melalui publikasi karya ilmiah dalam kurun waktu tertentu.

\section{KAJIAN PUSTAKA}

Beragam penelitian yang berkaitan dengan bibliometrik telah banyak dilakukan. Pada penelitian ini, peneliti menggunakan tiga hasil riset yang sebelumnya telah dilakukan oleh peneliti lain untuk menunjang penelitian ini sebagai tinjauan literatur. Penelitian pertama dilakukan oleh Tupan (2016), dalam kajian yang ia lakukan dengan melakukan penelusuran menggunakan database Scopus menggunakan kata kunci agricultural dan Indonesia, Tupan menemukan bahwa jumlah publikasi hasil penelitian bidang pertanian pada Scopus tahun 1995-2015 mengalami peningkatan secara signifikan dan terbanyak dipublikasikan dalam Bulletin of Indonesian Economic Studies. Selanjutnya, ia juga menemukan hasil penelitian bahwa penyumbang publikasi terbanyak hasil penelitian bidang pertanian di Indonesia yang terindeks di Scopus adalah Institut Pertanian Bogor (IPB). Dalam penelitian yang ia lakukan ditemukan juga bahwa peneliti asing yang paling produktif mempublikasikan hasil penelitian bidang pertanian di Indonesia adalah Tscharntke. Sedangkan. peneliti dari Indonesia yang paling produktif adalah Parikesit dan Buchori. Peneliti bidang pertanian di Indonesia terbanyak bekerja sama dengan civitas dari Amerika Serikat disusul dengan civitas dari Australia dan Jepang. Untuk subjek terbanyak pada hasil penelitian bidang pertanian adalah Agricultural and Biological Sciences. Melalui visualisasi network dapat menunjukkan bahwa peta perkembangan penelitian bidang pertanian terbagi menjadi 3 kluster. Kluster 1 terdiri dari 149 topik, kluster 2 terdiri 105 topik, dan kluster 3 terdiri 48 topik.

Penelitian kedua dilakukan oleh Royani \& Idhani (2018), dari hasil penelitian yang telah dilakukan, Menunjukkan bahwa artikel terbanyak dimuat pada 2013 ialah sebanyak 12 judul dengan prosentase $24,49 \%$, 37 artikel dengan prosentase $75,51 \%$ yang ditulis oleh penulis lebih dari satu / kerja sama (kolaborasi) serta 12 artikel mempunyai prosentase sebesar $24,48 \%$ ditulis oleh penulis tunggal, serta nilai tingkat kolaborasi sebesar 0,7 . Berikutnya, dalam riset tersebut pula menampilkan sebanyak 6 tipe dokumen (1504 rujukan) disitir. Hasil riset tersebut pula menyimpulkan bahwa dari 49 artikel yang dimuat pada Jurnal Maritim Research in Indonesia, didominasi oleh penulis kolaborasi, 
dengan jurnal paling banyak disitir sebesar $(57,58 \%)$, dengan panjang artikel paling banyak pada kisaran $6-10$ halaman. Tidak hanya itu, untuk Klas DDC yang paling banyak merupakan klas 628 ialah kelas lingkungan yang memiliki jumlah 8 artikel ( 16,67\%)".

Penelitian ketiga dilakukan oleh Tupan \& Rachmawati (2018). Berdasarkan penelitian yang telah dilakukan, menunjukkan bahwa pertumbuhan publikasi ilmiah ilmu serta teknologi pangan di negara-negara ASEAN menunjukkan adanya peningkatan serta pertumbuhan paling tinggi terjadi pada tahun 2013 dengan jumlah 113 dokumen (14,71\%). Berikutnya, untuk publikasi paling banyak diterbitkan pada jurnal inti International Journal of Food Science And Technology dengan jumlah 240 publikasi. Universiti Putra Malaysia ialah lembaga penyumbang publikasi paling tinggi sebanyak 95 publikasi. Peneliti paling produktif berasal dari negeri Thailand antara lain Benjakul, S., Benjakul, S., Noomhorm, A, Therdthai, N., Devahastin, S. Thailand ialah negera yang sangat produktif dengan jumlah 310 publikasi. Pada penelitan tersebut pula menampilkan subjek yang paling banyak ialah Agricultural and Biological Sciences dengan jumlah 620 dokumen $(80,7 \%)$, Engineering berjumlah 318 (41,4\%), Biochemistry, Genetics and Molecular Biology berjumlah 112 dokumen (14,6\%), Immunology and Microbiology dengan jumlah 74 dokumen ( $9,6 \%)$ serta paling tinggi dalam bentuk artikel. Bersumber pada hasil visualisai network menampilkan hubungan antar topik mengelompok jadi 7 kluster.

Berikutnya, berkaitan dengan kajian bibliometrik, Ellegaard \& Wallin (2015) dalam Sidiq (2019) menguraikan bahwa analisis ataupun tata cara bibliometrik (bibliometrics) terkadang dapat disebut dengan sebutan scientometrics merupakan bagian dari metodologi evaluasi terhadap penilaian riset, serta dari bermacam literatur yang sudah banyak dihasilkan, dan memungkinkan untuk dilakukan analisis bibliometrik dengan memakai tata cara tertentu. Bidang kajian bibliometrika dapat menjabarkan tentang besaran serta keunggulan sesuatu bidang ilmu, lebih-lebih berkaitan dengan lembaga Pendidikan dengan menerapkan bermacam teori seperti analisis kepengarangan, analisis sitiran, webometrik (bibliometrik yang berbasis website), kerjasama kepengarangan (pengarang bersama), keusangan (keadaan usang) pada dokumen, faktor dampak, dan lain sebagainya (Tupan \& Rachmawati, 2018).

Ratna \& Nelisa (2012) menjelaskan bahwa Bibliometrika ialah kajian untuk mengukur produktivitas karya-karya ilmiah di bermacam bidang ilmu. Analisis bibliometrik pada intinya digunakan untuk menguraikan informasi bibliografi yang ada artikel/jurnal ataupun dalam terbitan yang lain secara kuantitatif.

Saat ini, pariwisata sudah jadi trend kehidupan manusia modern. Hal ini terjadi karena aktivitas manusia memiliki dimensi yang luas, antara lain tidak hanya untuk bersenang-senang dalam menikmati perjalanan, namun aktivitas ini pula bisa memunculkan kegiatan ekonomi, seni, serta budaya (Arjana, 2016). Soebagyo (2012) juga menjelaskan bahwa dalam usaha pengembangan pariwisata, terdapat empat bidang pokok antara lain adalah ekonomi, sosial, budaya dan lingkungan hidup.

Dalam kaitanya dengan pariwisata, juga terdapat berbagai unsur yang dapat menjadi focus kajian. Isdarmanto (2017) menyebut terdapat pelbagai unsur dalam pengembangan pariwisata yang berkelanjutan dan mutlak sangat menentukan, antara lain adalah daya tarik Daya Tarik Wisata, Fasilitas \& Jasa Pelayanan Wisata, Kemudahan untuk mencapai destinasi wisata, serta Keramah tamahan.

\section{METODE PENELITIAN}

Penelitian yang dilakukan oleh peneliti menggunakan deskriptif kuantitatif. Sedangkan untuk analisisnya menggunakan analisis bibliometrika dengan mengumpulkan hasil literatur scholarly journals yang diperoleh dari ProQuest dengan kata kunci "Tourism in Indonesia". Berdasarkan hasil penelusuran, peneliti memperoleh 56 hasil penelusuran karya ilmiah yang kemudian di export dalam format RIS dan diolah menggunakan VOSviwer. Kepariwisataan di Indonesia dalam hal ini memuat berbagai kajian yang luas namun ada beberapa batasan khusus didalamnya. (Isdarmanto, 2017) menjelaskan bahwa terdapat pelbagai batasan pengertian pokok dalam membicarakan kepariwisataan. Batasan ini digunakan sebagai titik tolak yang fokus dalam pembahasan. Batasan-batasan tersebut antara lain berkaitan dengan Batasanbatasan tersebut antara lain berkaitan dengan Pariwisata, Wisatawan, Produk Wisata, Atraksi Wisata, Sarana Wisata, serta Prasarana Wisata.

\section{HASIL DAN PEMBAHASAN}

\section{Gambaran Umum ProQuest}

ProQuest ialah gabungan perusahaan, tiap- tiap diawali oleh inovator yang termotivasi 
untuk menuntaskan tantangan bagi perpustakaan/peneliti. Selaku pusat kewirausahaan, sejarah kolektif ProQuest memetakan evolusi industri informasi, sejak awal profesi perpustakaan sampai peralihan tanpa henti dari sumber energi cetak ke elektronik (ProQuest, n. d.- b). ProQuest ialah mitra utama bagi pemegang konten dari segala jenis, melindungi dan membolehkan akses ke data mereka yang berlimpah dan beragam. Kemitraan tersebut telah membangun koleksi (konten) yang tumbuh saat ini mencakup 90.000 sumber otoritatif, 6 miliar halaman digital, dan berlangsung selama 6 abad. Ini mencakup koleksi disertasi dan tesis paling banyak di dunia; 20 juta halaman dan 3 abad pesan berita (koran) baik secara global, nasional, regional serta khusus; lebih dari 450.000 ebook; koleksi teragregasi yang melimpah dari jurnal dan majalah ilmiah terpenting di dunia; dan brankas unik koleksi sejarah (digital) dari perpustakaan dan museum besar, serta berbagai organisasi semacam Arsip Kerajaan, Associated Press, dan Asosiasi Nasional buat Kemajuan Orang ( ProQuest, n. d.- a). Berdasarkan hasil penelusuran peneliti melalui ProQuest menggunakan kata kunci "Tourism in Indonesia" dan menggunakan filter penelusuran Scholarly Journals dan memiliki subject tourism menghasilkan 56 hasil penelusuran karya ilmiah. Penerapan tanda Apostrophe (“...”) juga dimaksudkan agar hasil penelusuran lebih spesifik menyesuaikan dengan kata kunci yang dicari.

\section{Gambaran Umum VOSviewer}

VOSviewer adalah perangkat lunak untuk membangun dan memvisualisasikan jaringan bibliometrik. Jaringan ini misalnya dapat mencakup jurnal, peneliti, atau publikasi individu, dan mereka dapat dibangun berdasarkan kutipan, penggabungan bibliografi, kutipan bersama, atau hubungan penulisan bersama. VOSviewer juga menawarkan fungsionalitas penambangan teks yang dapat digunakan untuk membangun dan memvisualisasikan jaringan kejadian bersama dari istilah-istilah penting yang diekstrak dari literatur ilmiah (VOSviewer, n.d.).

\section{Analisis Berdasarkan Kata Kunci (Co- Occurrence)}

Berdasarkan data yang telah diperoleh oleh peneliti dari ProQuest, dengan Jumlah minimum kemunculan kata kunci 5 dari 544 kata kunci, terdapat 17 kata kunci yang memenuhi ambang batas, dengan penjabaran sebagai berikut :

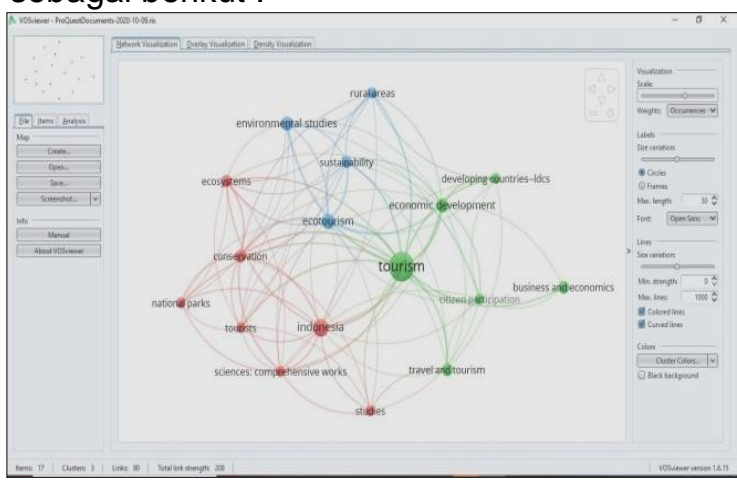

Sumber : Hasil Visualisasi Menggunakan VOSViewer

Gambar 1. Hasil Network Visualizaton

Dari 17 kata kunci yang dihasilkan pada gambar diatas, peneliti mendapati 3 cluster dalam visualisasi tersebut diantaranya ialah :

Cluster 1 yaitu (Conservation, Ecosystems, Indonesia, National Parks, Sciences: Comprehensive Works, Studies, Tourists). Cluster 2 yaitu (Business and Economics, Citizen Participation, Developing Countries-Idcs, Economic Development, Tourism, Travel and Tourism). Kemudian untuk Cluster 3 memuat (Ecotourism, Environmental Studies, Rural Areas, Sustainability).

\section{Analisis Berdasarkan Pengarang (Co- Author)}

Berdasarkan penelitian yang telah dilakukan, peneliti memperoleh total 159 penulis karya ilmiah yang terbagi kedalam 56 hasil penelusuran Scholarly Journal. Dari 159 penulis tersebut, hanya terdapat 23 penulis yang memenuhi ambang batas jejaring kepenulisan seperti gambar berikut ini :

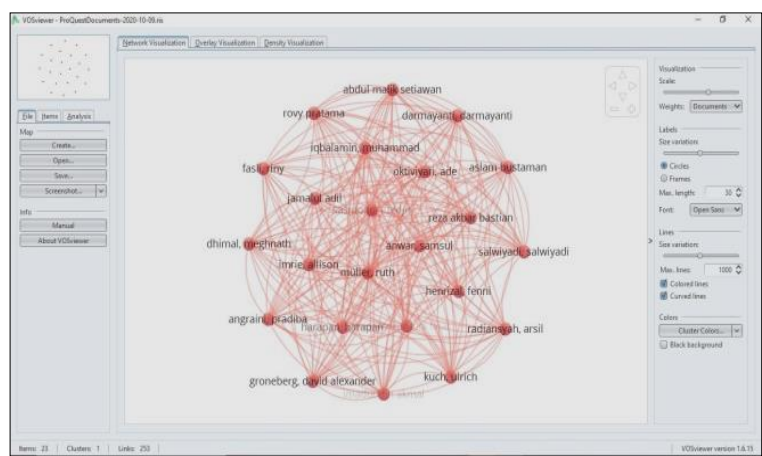

Sumber : Hasil Visualisasi Menggunakan VOSViewer

Gambar 2. Hasil Analisis Kepengarangan

Gambar diatas menunjukkan bahwa terdapat 23 pengarang (Co-Authorship) dalam 
penulisan karya ilmiah yang terbagi dalam 1 Cluster pada Tabel dibawah ini :

Tabel 1. Cluster Co-Authorship

\begin{tabular}{|c|c|c|c|c|}
\hline No & Nama Penulis & Judul & $\begin{array}{l}\text { Nama } \\
\text { Jurnal }\end{array}$ & $\begin{array}{l}\text { Thn., } \\
\text { (Vol.) }\end{array}$ \\
\hline 1 & $\begin{array}{l}\text { Harapan, } \\
\text { Harapan;Anwa } \\
\text { r, } \\
\text { Samsul;Aslam } \\
\text { Bustaman;Radi } \\
\text { ansyah, } \\
\text { Arsil;Angraini, } \\
\text { Pradiba;Fasli, } \\
\text { Riny;Salwiyadi, } \\
\text { Salwiyadi;Reza } \\
\text { Akbar } \\
\text { Bastian;Oktiviy } \\
\text { ari, } \\
\text { Ade;Imaduddin } \\
\text { Akmal;Iqbalami } \\
\text { n, } \\
\text { Muhammad;Ja } \\
\text { malul } \\
\text { Adil;Henrizal, } \\
\text { Fenni;Darmaya } \\
\text { nti, } \\
\text { Darmayanti;Ro } \\
\text { vy } \\
\text { Pratama;Jonny } \\
\text { Karunia } \\
\text { Fajar;Abdul } \\
\text { Malik } \\
\text { Setiawan;Imrie } \\
\text { Allison;Kuch, } \\
\text { Ulrich;Gronebe } \\
\text { rg, David } \\
\text { Alexander;Sas } \\
\text { mono, R } \\
\text { Tedjo;Dhimal, } \\
\text { Meghnath;Müll } \\
\text { er, Ruth }\end{array}$ & $\begin{array}{l}\text { Commu } \\
\text { nity } \\
\text { Willingn } \\
\text { ess to } \\
\text { Particip } \\
\text { ate in a } \\
\text { Dengue } \\
\text { Study in } \\
\text { Aceh } \\
\text { Provinc } \\
\text { e, } \\
\text { Indones } \\
\text { ia }\end{array}$ & $\begin{array}{l}\text { PLoS } \\
\text { One }\end{array}$ & $\begin{array}{l}2016 \\
(11)\end{array}$ \\
\hline
\end{tabular}

Dalam kaitannya produktivitas kepenulisan hanya terdapat 1 penulis yang memiliki 3 karya tulis yaitu (Jaelani, Aan), disusul (Wisansing, Jutamas) dengan 2 karya tulis dan (penulis) lainnya memiliki 1 karya tulis. Deskripsi karya penulis paling produktif dapat dijabarkan pada tabel dibawah ini :

Tabel 2. Penulis Paling Produktif

\begin{tabular}{llll}
\hline $\begin{array}{l}\text { Nama } \\
\text { Penulis }\end{array}$ & Judul & $\begin{array}{l}\text { Nama } \\
\text { Jurnal }\end{array}$ & $\begin{array}{l}\text { Thn., } \\
\text { (Vol.) }\end{array}$ \\
\hline Jaelani, Aan & Halal & Interna & 2017 \\
& Tourism & tional & $(7)$ \\
& Industry in & Revie & \\
& Indonesia: & w of & \\
& Potential and & Manag & \\
\hline
\end{tabular}

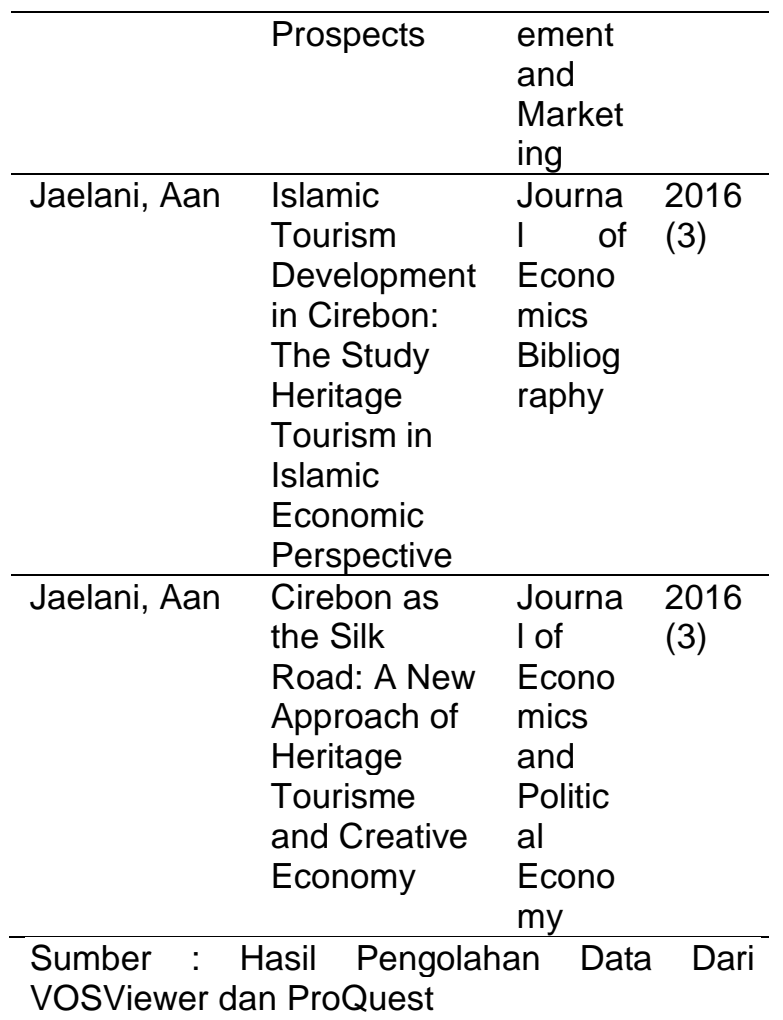

\section{Perkembangan Scholarly Journals Sesuai Tahun Terbitan}

Tabel 3. Perkembangan Terbitan Scholarly Journals

\begin{tabular}{ccc}
\hline No & Tahun & $\begin{array}{c}\text { Jumlah } \\
\text { Terbitan }\end{array}$ \\
\hline 1 & 1993 & 1 \\
\hline 2 & 1995 & 1 \\
\hline 3 & 2005 & 2 \\
\hline 4 & 2008 & 4 \\
\hline 5 & 2009 & 1 \\
\hline 6 & 2011 & 1 \\
\hline 7 & 2012 & 2 \\
\hline 8 & 2014 & 3 \\
\hline 9 & 2015 & 3 \\
\hline 10 & 2016 & 9 \\
\hline 11 & 2017 & 6 \\
\hline 12 & 2018 & 7 \\
\hline 13 & 2019 & 11 \\
\hline 14 & 2020 & 5 \\
\hline & Total & $\mathbf{5 6}$ \\
\hline
\end{tabular}

Sumber : Data Primer ProQuest diolah Oktober 2020

Berdasarkan tabel diatas menggambarkan bahwa sejak tahun 1993-2020 mengalami fluktuatif terhadap publikasi yang diterbitkan. Dari tahun 1993-Awal Oktober 2020 jumlah publikasi terbanyak terdapat pada tahun 2019 yaitu sebanyak 11 terbitan. 


\section{PENUTUP}

Berdasarkan hasil penelitian diatas, penulis dapat menyimpulkan bahwa dari kata kunci "Tourism in Indonesia" ditemukan 17 kata kunci yang terbagi dalam 3 cluster. Kemudian, Pada jejaring kepenulisan terdapat 1 cluster yang terdiri dari 23 penulis dan yang paling produktif adalah Jaelani, Aan dengan 3 dokumen hasil karya artikel jurnal. Publikasi terbanyak terjadi pada tahun 2019 sebanyak 11 scholarly journals. Berdasarkan simpulan diatas, penulis dapat memaparkan kelebihan dan memberikan saran bahwa melalui penelitian ini, kedepan untuk penelitian lanjutan memiliki peluang-peluang yang dapat dimanfaatkan untuk penelitian selanjutnya misalnya penelitian pariwisata di Indonesia dapat dikaitkan dengan kata kunci, subjek, bidang lain atau yang sesuai hasil visualisasi menggunakan VOSViewer berkaitan dengan Conservation, Ecosystems, Indonesia, National Parks, Sciences : Comprehensive Works, Studies, Tourists, Business and Economics, Citizen Participation, Developing Countries-ldcs, Economic Development, Tourism, Travel and Tourism, Ecotourism, Environmental Studies, Rural Areas, Sustainability. Dalam penelitian ini hanya difokuskan pada aspek Co-Occurence (kata kunci) dan Co-Authorship (kolaborasi penulis), sehingga memungkinkan penelitian lebih lanjut dapat dilakukan oleh peneliti lainnya untuk melihat aspek lain misalnya berkaitan dengan Citation, Bibliographic Coupling, Co-Citation dan lainnya berkaitan dengan kajian analisis bibliometrika yang berkaitan dengan kata kunci penelusuran "Tourism in Indonesia".

\section{DAFTAR PUSTAKA}

Arjana, I. G. B. (2016). Geografi Pariwisata dan Ekonomi Kreatif. Rajawali Pers.

Damanik, J. (2017). Pariwisata Indonesia Antara Peluang dan Tantangan. Pustaka Pelajar.

Ellegaard, O., \& Wallin, J. A. (2015). The bibliometric analysis of scholarly production: How great is the impact? Scientometrics.

https://doi.org/10.1007/s11192-015-1645$z$

Hermantoro, H. (2011). Creative-Based Tourism: Dari Wisata Rekreatif Menuju Wisata Kreatif. Aditri.

Isdarmanto. (2017). Dasar-Dasar Kepariwisataan dan Pengelolaan Destinasi Pariwisata.

ProQuest. (n.d.-a). About - Who We Are.
Retrieved October 28, 2020, from https://about.proquest.com/about/whowe-are.html

ProQuest. (n.d.-b). ProQuest - History \& Milestones. Retrieved January 22, 2021, from

https://about.proquest.com/about/historymilestones/

Ratna, E., \& Nelisa, M. (2012). Artikel Dalam Jurnal Bidang Sastra Indonesia. 95-107.

Royani, Y., \& Idhani, D. (2018). Analisis Bibliometrik Jurnal Marine Research in Indonesia 1. Marine Research in Indonesia, 25(4), 63-68.

Sidiq, M. (2019). Panduan analisis bibliometrik sederhana.

June. https://doi.org/10.13140/RG.2.2.15688.37 125

Soebagyo, S. (2012). Strategi pengembangan pariwisata di Indonesia. Liquidity. http://ojs.itb-

ad.ac.id/index.php/LQ/article/view/145

Suryadana, M. L., \& Octavia, V. (2015). Pengantar Pemasaran Pariwisata. Alfabeta.

Tupan. (2016). Pemetaan Bibliometrik dengan VOSViewer Terhadap Perkembangan Hasil Penelitian Bidang Pertanian di Indonesia. Visi Pustaka, 18(3), 217-230.

Tupan, T., \& Rachmawati, R. (2018). Analisis Bibliometrik IImu dan Teknologi Pangan: Publikasi Ilmiah dl Negara-Negara ASEAN. Khizanah Al-Hikmah: Jurnal IImu Perpustakaan, Informasi, Dan Kearsipan, 6(1), 26-40. https://doi.org/10.24252/kah.v6i1a4

VOSviewer. (n.d.). VOSviewer - Visualizing scientific landscapes. Retrieved October 10, 2020, from https://www.vosviewer.com/ 